\title{
The Impact of the Mining Region's Ecology on Human Professional Development
}

\author{
Olga Nikiforova ${ }^{1}$, Tatyana Yakushina ${ }^{1}$, and Rashit Mamedov ${ }^{1}$ \\ ${ }^{1}$ T.F. Gorbatchev Kuzbass State Technical University, 650000, Kemerovo, Russian Federation
}

\begin{abstract}
The article actualizes the problem of improving professional environmental development in the regions of environmental risk. The unfavorable environmental situation in the mining regions of the country, including Kuzbass, necessitates the search for sustainable development of coal basins that can ensure a balanced and balanced interaction of environmental and economic factors. The paper lists the factors that contribute to the actualization of continuous environmental education; the article describes the stages of professional development, leading to the improvement of the status of environmental education and education of all segments of the population.
\end{abstract}

\section{Introduction}

The influence of the ecology of the mining region on the professional development of a person becomes an important scientific and practical problem in modern society, due to the fact that the idea of actualization of a new place and the role of environmental education in the conditions of the developing market economy of the mining region, the importance of giving it a higher place and importance.

The problems of human interaction with nature have always been the subject of attention of researchers of various Sciences, including Economics. The existence of man is always connected with his desire to create, not always having an idea of the full picture of the world and, solving numerous short-term tasks, be it the extraction of food or coal mining, the vector of his creation and development was directed towards the environment, which man has always exploited in accordance with their needs and interests. At the turn of the third Millennium, the horizons of such human activity, manifested in the threat of environmental disaster and posing a danger to all mankind, were clearly outlined. Modern society - a society of consumers, people tend to consume, not save. Thus, the main contradiction between economic and environmental development is that, on the one hand, the economy must develop, on the other hand, this development has harmful consequences for the environment and human beings.

In order to preserve the society and the human being, there is an acute problem of changing the view of the world, rethinking the old and finding new ways of its development, including in the issues of interaction between man and nature. On a global scale - this is a contradiction between the economy and the environment, which can significantly affect the essence of professional development of a person engaged in activities in the mining industry. 
Improving the status of professional environmental education and awareness is becoming a fundamental pillar of building a system of sustainable development of mining and other industrial regions.

\section{Results and discussion}

The feature of the professional development specialist in the mining industry should be considered its modern state, characterized by such processes as the market economy, diversification, coal company towns, "the city is mine", etc. on the one hand, they are the ways of preserving, survival or development of the mining industry, and on the other, are in conflict with the threat of environmental disaster, a fact which no doubt neither the industry nor residents of the mining regions.

Based on the opinion of M. E. Kunyavsky and others [4], who argue that the diversification process should be focused on market priorities, the end result of which is the production of competitive products, it should be understood that this implies the relevance of professional development of a specialist capable of ensuring the production of such products. First of all, we are talking about environmental risks in relation to both man and nature.

Analysis of identified sources [2, 6, 8] allows one to note that:

- the global financial crisis has affected all spheres of life and has repeatedly exacerbated the existing problems of mono-profile settlements, for example, coal mining. The city-forming coal enterprises, as the export-resource enterprises in the majority, sharply reduced the volume of production or were forced to stop their work completely;

- residents of single-industry towns were in the most economically and socially vulnerable position. The social consequences of the crisis are an increase in the level of officially registered and hidden unemployment, a sharp decline in the level and quality of life, the outflow of the economically active population, and an increase in social tension. The situation with employment in mono-profile municipalities is complicated to a large extent (compared to large cities) by a very limited number and range of choice of places of employment;

- the main problems of mono-profile cities, caused by the rupture of previously established stable production ties with suppliers and consumers, the decline in production, the lack of competitiveness of the main products, the high share of non-core assets in the ownership of enterprises, the close connection of the city's infrastructure with the work of the enterprise, have worsened;

- the problems of ecology of nature due to the lack of funds for its preservation, and human ecology due to its socio-psychological and professional destruction have become significantly aggravated.

The formation of single-industry towns, including in the Russian mining industry, was historically and economically conditioned by the evolution of socio-economic systems, the life cycle of industries and economic activities. Historically, single-industry towns have emerged as «manufacturing towns», «mine towns», and, as a rule, in new areas of economic development. Gradually, rapid development was replaced by stability, and then stagnation, as the city-forming enterprise and its products become unclaimed.

A typical example is the coal company towns of the Kemerovo region and other regions. When they were created in the 1930-1950-ies, coal was truly the «bread of industry», a vital raw material for rapid industrialization. The transition from the industrial type of growth to the post-industrial type, the reduction in the need for coal, the displacement of its gas, the sharp economic decline in Russia in the 1990s put coal cities in an extremely difficult situation. Currently, they are critically dependent on coal demand and prices in the world market, while the prospects for expanding markets are extremely 
illusory. A similar trajectory of development is also inherent in metallurgical, chemical, machine-building city-forming enterprises and the corresponding single-industry towns $[1$, $9,10]$.

The diversification allows to expand the activity of industrial enterprises and related industries outside their core business. Therefore, diversification is designed to help enterprises to move to the creation of diversified production, which is a key part of the market economy, which has a significant impact on competition, the division of labor in the production of products, the efficiency of industrial production. The boundaries of diversification are variable. The more the industrial enterprise has technical and production capabilities and areas of production activity, the higher the level of diversification.

It should be understood that diversification can not fully reduce the risk of changes in production and marketing activities, but it makes it possible to significantly reduce it. Diversification leads to a comprehensive adjustment of the main production activities of the enterprise, and to a reorientation of the strategy of behavior in the market. The experience of a number of leaders of manufacturers of industrial products shows that diversification makes it possible:

-to reduce economic risks at deterioration of economic indicators on the main production activity as failures in one type of production and economic activity can be filled in another; -flexibly change the direction of application of financial resources from areas with low attractiveness to a more promising type of business;

-to invest free financial resources in other areas of production activities;

-to expand the existing production and economic activity and to form new directions in production, i.e. to achieve positive results due to economies of scale;

-ensure full capacity utilization;

-adapt to market conditions, create a mechanism to counter competitors, reduce dependence on business partners;

-to expand the range of products by optimizing the production process and the introduction of new technologies, etc.

It can also be assumed that diversification makes it possible to reduce environmental risks even with the deterioration of various economic indicators for the main production activity, since failures in one type of production and economic activity can be compensated in another. But the main thing is that to solve environmental problems, it is necessary to synthesize socio-economic opportunities, change the social policy of the state and, most importantly, the consciousness of people, including at the stage of their professional development as specialists.

The global environmental future depends on the extent to which all the measures taken will be implemented in practice, how the General economic decisions will be combined with the specifics of the environmental situation in the country as a whole and in each region separately. An example of such a path is China, which, being not the most developed country, has achieved positive results in environmental development in a relatively short period of time.

At present, it is obvious that economic growth cannot be stopped, because there is a feedback: one of its sources is the quantity and quality of natural resources themselves. The contradiction between «environment and economic development» is not so much a dilemma: either economic development or a clean environment, but rather the need to achieve a common goal: to ensure a level of development that would imply not only the creation of material goods necessary for society. One of the results of their activities was the development of common solutions to environmental problems. The concept of transition of the Russian Federation to sustainable development (app. Decree of the President of the Russian Federation №440 from 01.04.1996), as an alternative to economic growth, is increasingly discussed in scientific papers and policy documents of the club of 
Rome and the UN International Commission on environment and development. «Sustainable development» from the point of view of its supporters is an ecological and economic model of society development, which provides for meeting the needs of current generations without compromising the ability of future generations to meet their own needs $[3,5,7]$. The process of sustainable development is a qualitatively new stage in the evolution of ecological and economic relations in the Russian Federation, associated with the construction of a society capable of ensuring a balanced and balanced interaction of environmental and economic factors of development.

Basic principles of the Concept of sustainable development (t.1) indicate the importance of integration and unity of the two Sciences: ecology and Economics, the need for an inextricable link between these types of human activity, especially in the field of vocational education as the basis for the formation of a specialist competence in the field of ecology.

Table 1. Basic principles of the Concept of sustainable development.

\begin{tabular}{|l|l|}
\hline Principles of green development & Principles of economic development \\
\hline Greening the economy & Transition to eco-technologies and ecotechnics \\
\hline $\begin{array}{l}\text { Recognition of unity and variety of options of } \\
\text { socio-economic and ecological development of } \\
\text { the different countries and nations }\end{array}$ & $\begin{array}{l}\text { Searching of such way of development which } \\
\text { would minimize costs of ecological } \\
\text { development }\end{array}$ \\
\hline $\begin{array}{l}\text { The statement of a primate of harmony } \\
\text { concerning the "society-the nature" system }\end{array}$ & $\begin{array}{l}\text { Substitution for the system "spend-benefits" } \\
\text { (based on the analysis of profits and losses from } \\
\text { environmental pollution) the principle } \\
\text { "expenses - efficiency" (need of expenses for } \\
\text { ensuring efficiency of ecological production } \\
\text { and reproduction) }\end{array}$ \\
\hline $\begin{array}{l}\text { The policy of optimally effective use of natural } \\
\text { resources, careful attitude to the biosphere } \\
\text { which is combined with care of future } \\
\text { generations }\end{array}$ & $\begin{array}{l}\text { Ecological forecast and monitoring: observation } \\
\text { of a condition of natural resources and } \\
\text { prediction of the possible behavior of natural } \\
\text { systems determined by natural processes and } \\
\text { impact of the person on them }\end{array}$ \\
\hline $\begin{array}{l}\text { Statement as a basis of socio-economic } \\
\text { development of freedom, but not violence; } \\
\text { humanity, but not hostility }\end{array}$ & \begin{tabular}{l} 
Ecological safety of economy \\
\hline
\end{tabular}
\end{tabular}

The UN summit on sustainable development, held in Johannesburg in 2002, drew attention to the role of education in the transition to sustainable development. The principles of sustainable development can be the result of environmental development and continuous environmental education as an innovative system of training a modern specialist.

Therefore, the professional formation and development of a specialist in the conditions of «education through life» (schools, colleges, universities, additional education) should ensure the spread of environmental education and education is not a secondary and additional act, but a key, in connection with the enormous problems with the environment and their increasing growth in a market economy. This requires:

- restoration of the ecology course in the secondary school program;

- inclusion of the elements of the environment in all curricula of middle and high school;

- inclusion of ideas about the value of life-supporting functions of natural systems in the process of continuous environmental education;

- inclusion of the issues of formation of ecological culture, ecological education and enlightenment in the Federal target, regional and local programs of development of territories;

- formation of an effective system of promotion of sustainable development ideas; 
- state support for education and education systems that provide environmental education and training;

- development of the system of environmental training of specialists of environmental services, law enforcement and judicial bodies;

- development of the system of institutions of additional ecological and biological education, children's ecological camps;

- support for youth environmental movements («green patrol», «blue patrol», unnat movement, etc.).

It should be noted that the definition of sustainable development, pointing to the strategic goal, has a low practical orientation and does not indicate a specific path for action and the practical effect of them. It seems that within the framework of the introduction of environmental vocational education in the mining region, environmental and economic effects will be quite diverse and significant (t. 2).

Table 2. Environmental and economic effects of the sustainable development system.

\begin{tabular}{|l|l|}
\hline \multicolumn{2}{|c|}{ Sustainable development } \\
\hline $\begin{array}{l}|c| \\
\text { Environmental-oriented activities of business } \\
\text { entities }\end{array}$ & Increasing the competitiveness of the region \\
\hline Ecological attractiveness of the region & $\begin{array}{l}\text { Increase of investment attractiveness of the } \\
\text { region }\end{array}$ \\
\hline $\begin{array}{l}\text { Conservation and restoration of natural } \\
\text { resources }\end{array}$ & Labour productivity growth \\
\hline Improving the health of the population & Improving the safety of production \\
\hline Reduction of morbidity and disability & $\begin{array}{l}\text { Reducing the cost of sick leave and medical } \\
\text { care }\end{array}$ \\
\hline Improving quality of life & Reducing the level of disability, disability, etc \\
\hline
\end{tabular}

Of course, the subject of environmental and professional education policy should be staff at all levels - managers, specialists, workers, who, in addition to General ideas about the anthropogenic and anthropogenic factors of environmental impact, should have a sufficient level of environmental literacy, responsibility and personal interest.

The process of development of ecological and professional competence involves the following stages:

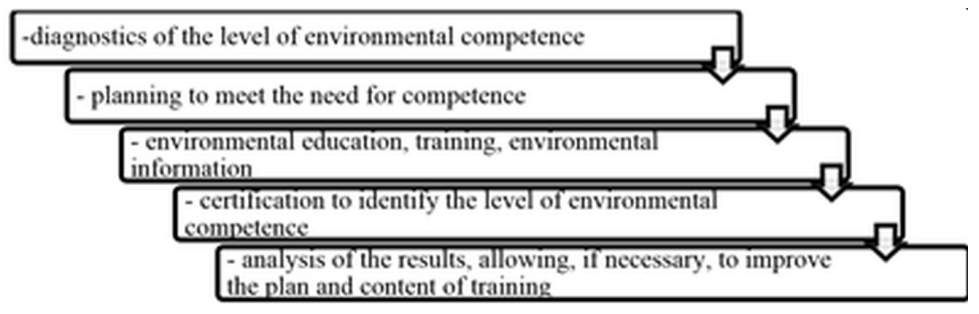

Fig. 1. The process of development of ecological and professional competence.

The result of the implementation of the above stages:

- applied environmental knowledge and skills;

- information on the environmental situation in the region (at the enterprise), on the legislative and regulatory framework of environmental activities, on the impact of the enterprise on the environment, public health;

- knowledge of duties, powers and responsibilities for non-compliance with environmental requirements;

- information on the results of the analysis of environmental violations;

- skills to prevent accidents and take measures to eliminate them; 
- information on environmental plans of the enterprise, the progress of their implementation;

- formation of environmental culture of employees that contribute to the strengthening of technological discipline at the expense of awareness of the necessity of solving environmental industrial problems.

A significant role in the formation of environmentally competent producers in the mining region belongs to professional technical education, aimed at familiarizing all students with materials and developments on sustainable development, indicators of environmental friendliness of technological processes. The program material of the disciplines should contain information about energy-saving technologies, energy efficiency, production and use of regenerative energy sources, secondary use of resources, reducing the environmental intensity of products and services, reducing environmental damage, reducing the negative impact on the environment, etc.

\section{Conclusion}

Thus, the environmental development of a specialist in a mining region is a continuous and multifactorial process that determines the evolution of society, its spiritual and material culture, the level and quality of life. Environmental safety, the predominance of people's environmental needs in the interests, continuous and professional education should be the factors of environmental development.

The modern economy of the mining region requires highly qualified personnel support in matters of environmental production. Environmental education for sustainable development should be an integral part of professional development, training of employees to perform production tasks.

\section{References}

1. R. Costanza, Conservation biology, Spoil, 6:1, 37 (1992)

2. Indicators of sustainable development: guidelines and methodologies (RTTS, Moscow, 2007)

3. D. Jeffrey, Sachs. The Age of Sustainable Development (Columbia University Press, New York, 2015)

4. M. E. Kunyavskii, I. M. Kublin, Thrust (International relations, Moscow, 2004)

5. O. L. Kuznetsov, B. E. Bolshakov, Sustainable development: natural and scientific principles (ST, Dubna, 2002)

6. M. Mesarovic, E. Pestel, Mankind at the turning point. Second report to the club of Rome (CTRA, Toronto, 1996)

7. J. Talberth, Tool for sustainable development, 94612, 31 (2006)

8. C. C. Williams, A. C. Millington, Geographical journal, 170:2, 99 (2004)

9. N. Zaruba, T. Fraltsova, T. Snegireva, E3S Web Conf., 21, 04028 (2017)

10. N. A. Zaruba, N. N. Egorova, P. D. Kosinsky, E3S Web Conf., 15, 04003 (2017) 